\title{
Flu shots for health and mental health
}

Keywords: immunology, HIV, hippocampal area, health, psychology

\section{Introduction}

Immunological investigations have identified the relationship between the flu and other viral infections and mood changes such as depressive-like behavior, cognitive deficits, sleepiness, and headache..$^{1-3}$ Cytokines are produced to combat infection during this time. While this cytokine is essential to destroy the infection, it has been measured to impair neuronal firing in the prefrontal cortex area, primarily the anterior hippocampal area. This brain region is important in learning, pleasure, memory and mood. Furthermore, investigations have determined the role of ongoing infections such as HIV and Herpes Simplex Virus Type 2 with increased release of stress hormones thus leading to many factors including negative affect. ${ }^{2-5}$ Thus, sickness behavior and cognitive dysfunction are associated. Further, research have identified that the cognitive dysfunction and negative affect are transient given their link to the release and metabolism of cytokine action.

Responsible medical advice includes the suggestion to obtain a flu shot. The physical discomfort of the flu, along with impending further health compromise places the patient at risk. Immunological studies have measured a reduction in the negative affect and cognitive dysfunction with interferon injections in basic animal studies. We learn that the treatment is effective physically from prescribed medications and these recent findings suggest that short circuiting of negative affect and cognitive dysfunction with treatment. Recently, public health messages have suggested that not only should one obtain a flu shot but that they should arrange for this when they feel they are in the best mood and most alert-seemingly to circumvent any temporary reactions from the immunization levels.

Perhaps a more effective message would be to consider not only obtaining the flu shot but also realizing the health risks would be compounded by mood changes and cognitive dysfunction. Public health and health psychology research provide many empirically valid intervention strategies to promote patient compliance. A central them to health promotion studies is education. The provision of accurate, understandable, simply stated messages to the patient that a flu shot will prevent the flu and any related mood/cognitive problems that correspond to this type of infection. Moving forward from here would be the provision of where one could obtain the flu shot, the free or nominal cost and the relative absence of side effects for many. In conclusion, education to a patient about obtaining a flu shot that
Volume 4 Issue 6 - 2017

Kathy Sexton-Radek

Elmhurst College, USA

Correspondence: Kathy Sexton-Radek, CBSM Suburban Pulmonary \& Sleep Associates, Elmhurst College, Illinois, USA, Email ksrsleep@aol.com

Received: October 29, 2017 | Published: December I, 2017

includes possible mood and cognitive dysfunction would be helpful to them in their decision to proceed with this important preventative medical intervention.

\section{Acknowledgements}

None.

\section{Conflicts of interest}

The author declares there is no conflict of interest.

\section{References}

1. Blank T, Detje CN, Spieß A, et al. Brain endothelial-and epithelialspecific interferon receptor chain 1 drives virus induced sickness behavior and cognitive impairment. Immunity. 2016;44(4):901-912.

2. Faulkner S, Smith A. A prospective diary study of the role of psychological stress and negative mood in the recurrence of herpes simplex virus (HSV1). Stress and Health. 2008;25(2):179-187.

3. Horn EE, Turkheimer E, Strachan E. Psychological distress, emotional stability, and emotion regulation moderate dynamics of herpes simplex virus type 2 recurrence. Annals of Behavioral Medicine. 2015;49(2):187-198.

4. Hsu P, Yolken RH, Beckie TM, et al. Association of depressed mood with herpes simplex virus-2 immunoglobulin-G levels in pregnancy. Psychosomatic Medicine. 2016;78(8):966-972.

5. McIntosh RC, Carrico A, Hurwitz BE, et al. Change in urinary cortisol excretion mediates the effect of angry/hostile mood on 9 month diastolic blood pressure in HIV+ adults. Journal of Behavioral Medicine. 2017;40(4):620-630. 